\title{
Factors influencing anaemia in dialysis patients. A special survey by the EDTA-ERA Registry
}

\begin{tabular}{|c|c|}
\hline W. Geerlings & $\begin{array}{l}\text { Leyenberg Ziekenhuis, The Hague, } \\
\text { Netherlands }\end{array}$ \\
\hline R. W. Morris & $\begin{array}{l}\text { Department of Public Health \& } \\
\text { Primary Care, Royal Free Hospital } \\
\text { School of Medicine, London, } \\
\text { United Kingdom }\end{array}$ \\
\hline F. P. Brunner & $\begin{array}{l}\text { Department für Innere Medizin, } \\
\text { Universität Basel, Switzerland }\end{array}$ \\
\hline H. Brynger & $\begin{array}{l}\text { Department of Surgery 1, } \\
\text { Sahlgrenska Sjukhuset, Göteborg, } \\
\text { Sweden }\end{array}$ \\
\hline J. H. H. Ehrich & $\begin{array}{l}\text { Medizinische Hochschule } \\
\text { Hannover, Germany }\end{array}$ \\
\hline W. Fassbinder & $\begin{array}{l}\text { Städtische Kliniken Fulda, } \\
\text { Germany }\end{array}$ \\
\hline G. Rizzoni & $\begin{array}{l}\text { Divisione di Nefrologia e Dialisi, } \\
\text { Ospedale Pediatrico Bambino Gesú, } \\
\text { Rome, Italy }\end{array}$ \\
\hline N. H. Selwood & $\begin{array}{l}\text { EDTA Registry, St Thomas' } \\
\text { Hospital, United Kingdom }\end{array}$ \\
\hline G. Tufveson & $\begin{array}{l}\text { Department of Surgery, Sahlgrenska } \\
\text { Sjukhuset, Göteborg, Sweden }\end{array}$ \\
\hline A. J. Wing & $\begin{array}{l}\text { Renal Unit, St Thomas' Hospital, } \\
\text { London, United Kingdom }\end{array}$ \\
\hline
\end{tabular}

\begin{abstract}
The European Dialysis and Transplantation Association-European Renal Association (EDTAERA) Registry conducted a special study on anaemia in dialysis patients because it seemed important to elucidate the various factors that influence the degree of anaemia and the use of regular transfusions in dialysis patients before the introduction of recombinant human erythropoietin ( $\mathrm{rHuEpo}$ ) for larger groups of patients. In a $20 \%$ sample of all patients recorded to have been dialysed throughout 1987 , statistically significant associations could be found by multifactorial analysis between haemoglobin $(\mathrm{Hb})$ concentration and age, sex, primary renal disease, type of treatment, hours of dialysis per week, and number of years on renal replacement therapy. The type of dialyser membrane did not seem to play a role (although there was weak evidence of an effect of the dialyser). Mean $\mathrm{Hb}$ concentration for dialysis patients differed between
\end{abstract}

Correspondence and offprtnt requests to: Dr N. P. Mallick, Chairman, EDTA Registry, St Thomas' Hospital, London SEl 7EH, UK. countries as did the transfusion policy. In view of the high costs of the rHuEpo treatment and potential sideeffects, factors such as method of dialysis and hours of haemodialysis per week should be taken into consideration in the treatment of anaemia in dialysis patients.

Key words: anaemia; sample study; EDTA Registry; dialysis patients; recombinant human erythropoietin (rHuEpo)

\section{Introduction}

The degree of anaemia in progressive renal failure increases as the glomerular filtration rate declines [1] and in patients treated by either haemodialysis or peritoneal dialysis, anaemia is almost invariably present. Diminished erythropoietin production seems to be the important pathogenetic factor, although other factors such as circulating inhibitors of erythropoiesis and decreased red cell survival have been described. Anaemia contributes considerably to morbidity and impairs the quality of life in patients on dialysis, and the introduction of rHuEpo was a major breakthrough in the management of patients with end-stage renal disease $[2,3]$.

Data concerning the influence of dialysis itself on the prevailing anaemia are conflicting $[4,5]$. A timerelated increase in haematocrit on maintenance haemodialysis has been described and in some cases has been associated with concurrent acute or chronic hepatitis $[6,7]$. It has often been suggested that acquired renal cysts may be responsible for an increase in haematocrit, but recently this correlation has been questioned [8-10].

To investigate transfusion dependency and the influence of several variables on anaemia in a large group of dialysis patients the EDTA Registry designed a special study concerning patients dialysed throughout 1987. In that particular year prescription of rHuEpo had barely started, and only a few patients in a minority of centres were receiving the drug. Hence there were no confounding effects of rHuEpo treatment. The database of the EDTA Registry made it possible to combine the results obtained in a special questionnaire with the extensive patient data already available from the Registry's file. 


\section{Subjects and methods}

At the end of 1987 there were 65200 patients on the Registry who were alive and had been treated throughout the year 1987 by dialysis (centre haemodialysis, home haemodialysis, intermittent peritoneal dialysis, or CAPD). Patients were sorted into random order within each centre in each country. After sorting, a 20\% sample was taken, resulting in 13040 patients selected. Each centre was sent a questionnaire with the name or initials of the randomly selected patients. The doctors responsible for these centres were asked to record the $\mathrm{Hb}$ concentration in December 1987. In addition they had to indicate for each patient the need of regular transfusion (defined as more than 1 unit of blood per 2-month interval). Information was also requested regarding bilateral nephrectomy and treatment with rHuEpo in 1987 and/or in 1988. Routine software tools made it possible to link the data from the special questionnaire with the other patient data already available on the Registry's file.

Of the special questionnaires concerning 13040 patients mailed in January 1989, 8625 were returned by the end of 1989. Of these, 7948 patients had $\mathrm{Hb}$ values recorded $(92.2 \%)$ whilst $565(6.6 \%)$ patients had to be excluded because of uncertainty regarding the absence of any changes in method of RRT during 1987, and another $515(6 \%)$ because they had undergone bilateral nephrectomy or had been treated with rHuEpo in 1987. This left $6869(79.6 \%)$ patients for analysis.

Data on type of dialyser most frequently used during 1987 for each individual, including the type of membrane and its ultrafiltration characteristics, were available for 4591 patients on haemodialysis. The variables listed in Table 1 were analysed by multiple regression against $\mathrm{Hb}$ concentration at 31 December 1987 and by logistic regression [11] against the need for transfusion during 1987.

The multifactorial analyses were carried out using the statistical package GLIM [12].

\section{Results}

\section{Validation of the sampling procedure}

Primary renal disease was selected as the profile characteristic to test the validity of the sampling procedure. In Figure 1 the distribution of primary renal disease in patients sampled can be compared to the distribution in all patients eligible for the sample. That primary renal diseases are similarly distributed in both groups

Table 1. Variables studied in the multifactorial regression analyses

Country of treatment
Sex
Age
Primary renal disease
Type of initial treatment
Type of most recent treatment
Length of time since start of treatment
Length of time on most recent treatment
Need for regular transfusions
Number of dialysis sessions per week
Hours of dialysis per week
Membrane type of dialyser
Ultrafiltration characteristics of the dialyser

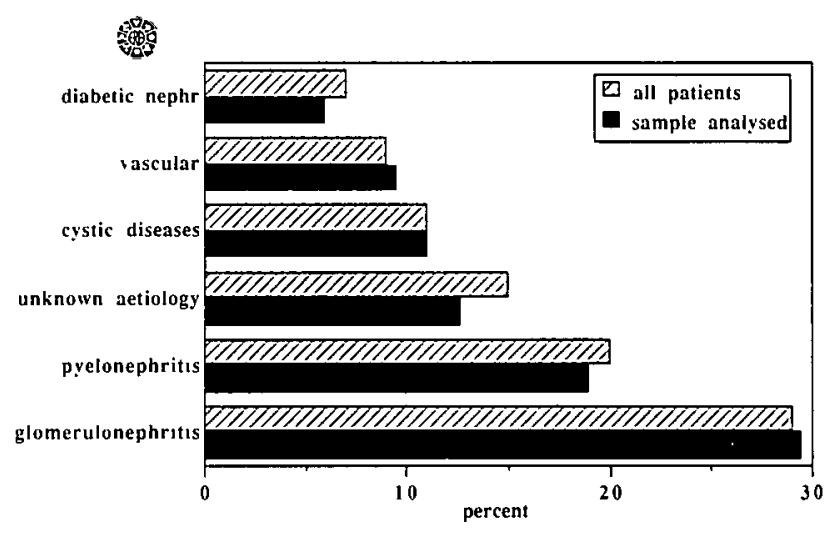

Fig. 1. Proportional distribution of different renal diseases among all patients dialysed throughout 1987 and among 6869 patients entered into the analyses.

of patients indicates that no bias for this factor was created by the sampling procedure.

\section{Countries}

In Table 2 the mean $\mathrm{Hb}$ concentrations are given according to the countries. A wide range is seen between countries such as the then German Democratic Republic and Czechoslovakia for whom mean $\mathrm{Hb}$ concentrations under $80 \mathrm{~g} / \mathrm{l}$ were recorded, whereas

Table 2. Mean haemoglobin concentration according to country. Countries with less than 10 patients were excluded

\begin{tabular}{lrl}
\hline & $n$ & Hb (g/dl) \\
& & Mean $\pm \mathrm{SD}$ \\
\hline Austria & & \\
Belgium & 88 & $83.8 \pm 17.2$ \\
Czechoslovakia & 224 & $88.4 \pm 16.5$ \\
Denmark & 123 & $78.3 \pm 14.2$ \\
Finland & 39 & $89.4 \pm 19.3$ \\
France & 38 & $90.7 \pm 21.1$ \\
Germany (East) & 1118 & $91.5 \pm 20.5$ \\
Germany (West) & 175 & $78.8 \pm 15.4$ \\
Greece & 1335 & $90.5 \pm 19.2$ \\
Hungary & 110 & $91.9 \pm 18.9$ \\
Ireland & 58 & $84.9 \pm 15.9$ \\
Israel & 31 & $83.6 \pm 17.7$ \\
Italy & 78 & $85.9 \pm 18.1$ \\
Netherlands & 1160 & $88.4 \pm 19.6$ \\
Norway & 108 & $87.7 \pm 22.2$ \\
Poland & 11 & $90.6 \pm 12.0$ \\
Portugal & 85 & $87.6 \pm 18.5$ \\
Spain & 187 & $87.6 \pm 20.4$ \\
Sweden & 913 & $89.0 \pm 21.3$ \\
Switzerland & 83 & $86.6 \pm 18.7$ \\
Turkey & 137 & $91.8 \pm 22.1$ \\
UK & 24 & $86.9 \pm 19.3$ \\
Yugoslavia & 311 & $90.8 \pm 21.9$ \\
Luxembourg & 253 & $82.8 \pm 18.2$ \\
Bulgaria & 12 & $87.8 \pm 14.6$ \\
Cyprus & 77 & $84.3 \pm 14.9$ \\
Tunisia & 14 & $80.4 \pm 16.2$ \\
Egypt & 38 & $87.4 \pm 21.5$ \\
Libya & 17 & $75.4 \pm 17.8$ \\
All & 13 & $75.3 \pm 16.6$ \\
\hline & 6869 & $88.7 \pm 19.9$ \\
\hline
\end{tabular}


France, the then Federal Republic of Germany, Greece, Switzerland, United Kingdom, and Scandinavian countries had mean $\mathrm{Hb}$ concentrations over $90 \mathrm{~g} / \mathrm{l}$.

\section{Age and sex}

$\mathrm{Hb}$ values were higher in males on renal replacement therapy (RRT) and tended to increase with age for both sexes (Figure 2). This is also reflected by the transfusion rate: $21 \%$ of all females were regularly transfused versus $13 \%$ of men.

\section{Primary renal disease}

The relationship between anaemia and primary renal disease is depicted in Table 3. Patients with polycystic kidney disease (ADPKD) showed significantly higher $\mathrm{Hb}$ concentrations. For all the other primary renal diseases no significant differences in haemoglobin concentration were observed. This is confirmed by the fact that regular transfusion was given to only $7 \%$ of patients with ADPKD, whereas $32 \%$ of patients with hereditary or familial nephropathy other than ADPKD received regular transfusions.

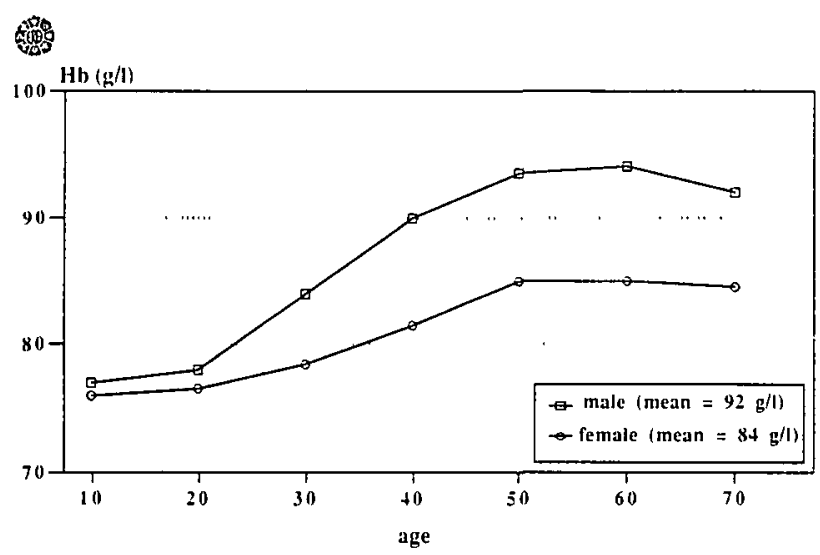

Fig. 2. Mean hacmoglobin concentration according to sex and age

Table 3. Mean haemoglobin concentration for selected primary renal diseases

\begin{tabular}{llr}
\hline Primary renal disease & $\begin{array}{l}\text { Hb }(\mathrm{g} / \mathrm{l}) \\
\text { Mean } \pm \mathrm{SD}\end{array}$ & \multicolumn{1}{c}{$n$} \\
\hline Aetiology uncertain & $86.5 \pm 18.9$ & 844 \\
Glomerulonephritis & $87.6 \pm 19.8$ & 1972 \\
Severe nephrotic syndrome in children & $78.2 \pm 18.8$ & 5 \\
Pyelonephritis/interstitial nephritis & $86.1 \pm 18.6$ & 1336 \\
Analgesic nephropathy & $86.3 \pm 17.9$ & 209 \\
Adult polycystic kidney disease & $01.6 \pm 21.4$ & 603 \\
Diabetic nephropathy & $90.2 \pm 17.9$ & 424 \\
Renal vascular disease & $88.5 \pm 17.6$ & 625 \\
Congenital/hereditary renal disease & $88.5 \pm 22.8$ & 86 \\
& & \\
All & $88.7 \pm 19.9$ & 6860 \\
\hline
\end{tabular}

Method of treatment and time spent on renal replacement therapy

In patients for whom CAPD was recorded as the most recent mode of $\mathrm{RRT}$ the mean $\mathrm{Hb}$ concentration was $96.1 \mathrm{~g} / \mathrm{l}$. Home haemodialysis patients displayed haemoglobin concentrations with a mean of $95.1 \mathrm{~g} / \mathrm{l}$. For hospital haemodialysis patients the mean $\mathrm{Hb}$ concentration was lower at $87.4 \mathrm{~g} / \mathrm{l}$, while IPD patients $(n=$ 27) had a mean haemoglobin concentration of $89.9 \mathrm{~g} / \mathrm{l}$.

In Table 4 the proportion of patients treated with hospital haemodialysis, home haemodialysis, CAPD, or IPD is shown for four ranges of $\mathrm{Hb}$ concentrations, showing that patients with $\mathrm{Hb}$ concentrations above $100 \mathrm{~g} / \mathrm{l}$ were more likely to be on home haemodialysis or CAPD. The same association was found regarding the need for transfusion which was lower in patients on home haemodialysis $(9 \%)$ and in patients on CAPD $(7 \%)$ compared with $18 \%$ of patients on hospital haemodialysis.

In Figure 3 the influence of length of time on RRT on $\mathrm{Hb}$ concentrations and need for transfusion is shown. Both variables were significantly related to time

Table 4. Percentage of patients in four different ranges of $\mathrm{Hb}$ concentration according to mode of treatment on 31 December 1987

\begin{tabular}{llllll}
\hline $\mathrm{Hb} \mathrm{g} / \mathrm{l}$ & $<60$ & $60-79$ & $80-100$ & $>100$ & $n=100 \%$ \\
\hline $\begin{array}{l}\text { Centre } \\
\text { HD }\end{array}$ & 4.0 & 36.8 & 36.8 & 22.4 & 5804 \\
Home & & & & & \\
HD & 3.2 & 27.6 & 32.4 & 36.8 & 535 \\
CAPD & 1.3 & 25 & 34.8 & 38.8 & 505 \\
\hline
\end{tabular}
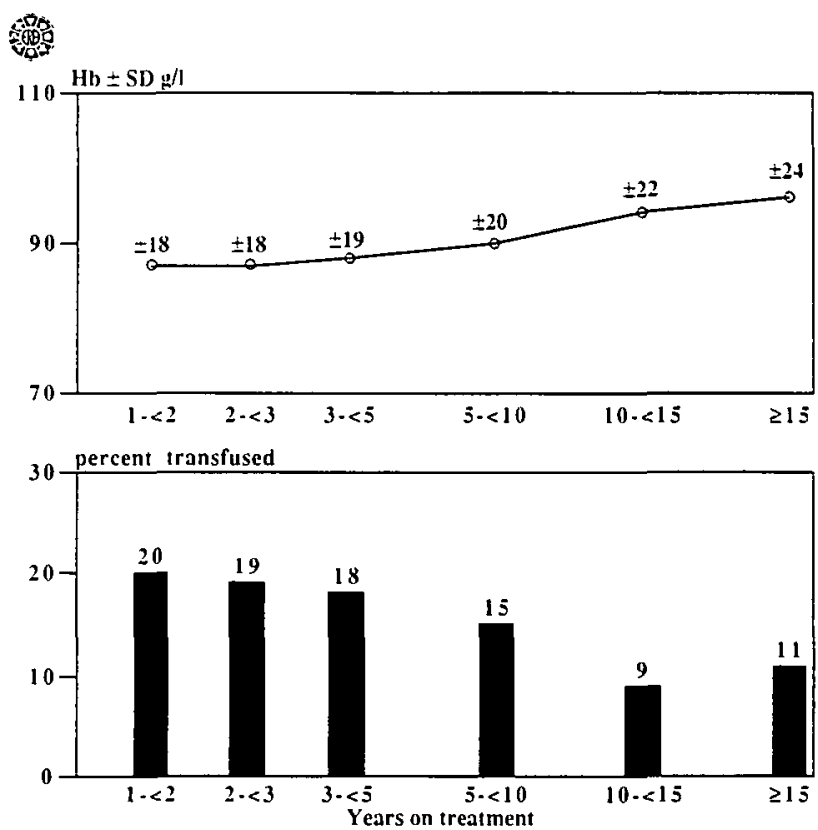

Fig. 3. Mean haemoglobin concentration and percentage of patients needing regular transfusion related to length of time on treatment in years. 
on RRT. In a more restricted analysis the influence of time spent on the most recent method of dialysis also showed a positive correlation with $\mathrm{Hb}$ concentration. There was a mean increase of $0.74 \mathrm{~g} / \mathrm{l}$ for every year of treatment for all dialysis modalities combined $(P<0.001)$, although the relationship had a correlation coefficient of only 0.12 , indicating the important influence of other parameters.

\section{Haemodialysis schedule and type of dialyser membrane}

While patients who were dialysed three times a week had higher haemoglobin concentrations than those dialysed twice a week, and this was also reflected by the need for transfusion (Figure 4), multifactorial analysis disclosed that the variable 'times per week' was itself not significantly correlated with $\mathrm{Hb}$ concentration, in contrast to the variable 'number of hours per week'. Hence three-times-weekly dialysis was associated with higher $\mathrm{Hb}$ concentrations because these patients were treated for more hours per week than those on twice-weekly dialysis.

The influence of the number of hours dialysis per week is apparent from Figure 5. In this study 11 or more hours of dialysis per week is associated with a steadily increasing $\mathrm{Hb}$ concentration. The variables 'mean blood flow/min' or 'dialyser area' were not studied.

To determine the effects of different types of dialysers, patients were grouped according to whether they had been treated most commonly with cellulose as opposed to non-cellulose membranes. This comparison did not yield any difference (mean $\mathrm{Hb}$ concentra-
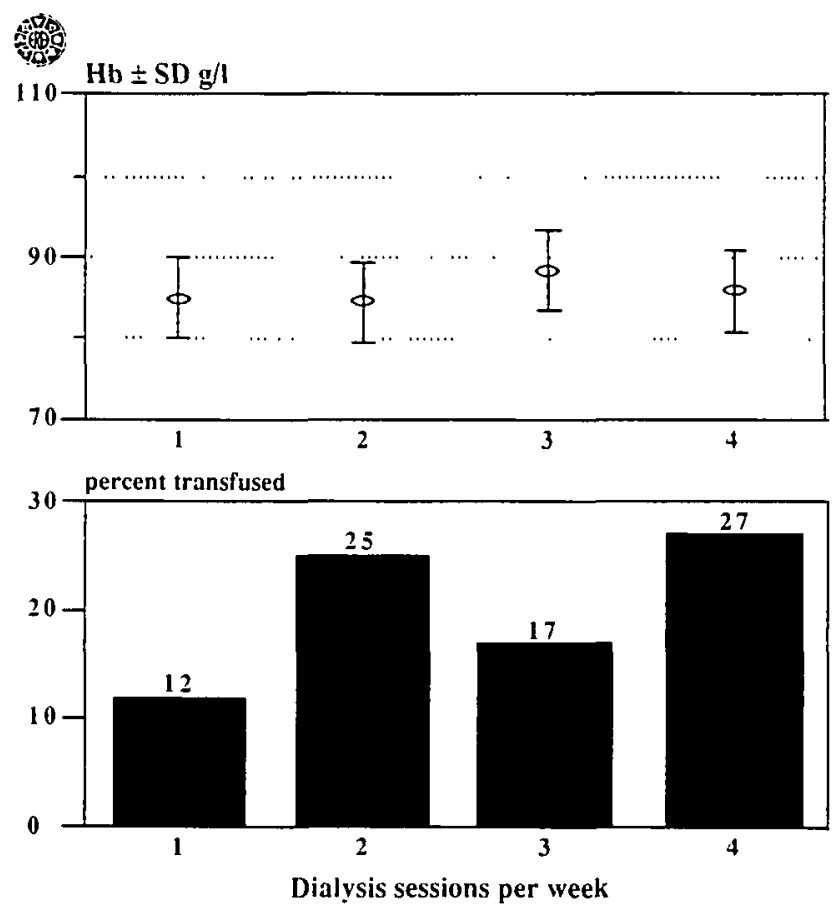

Fig. 4. Mean haemoglobin concentration and percentage of patients needing regular transfusion related to number of dialysis sessions per week.

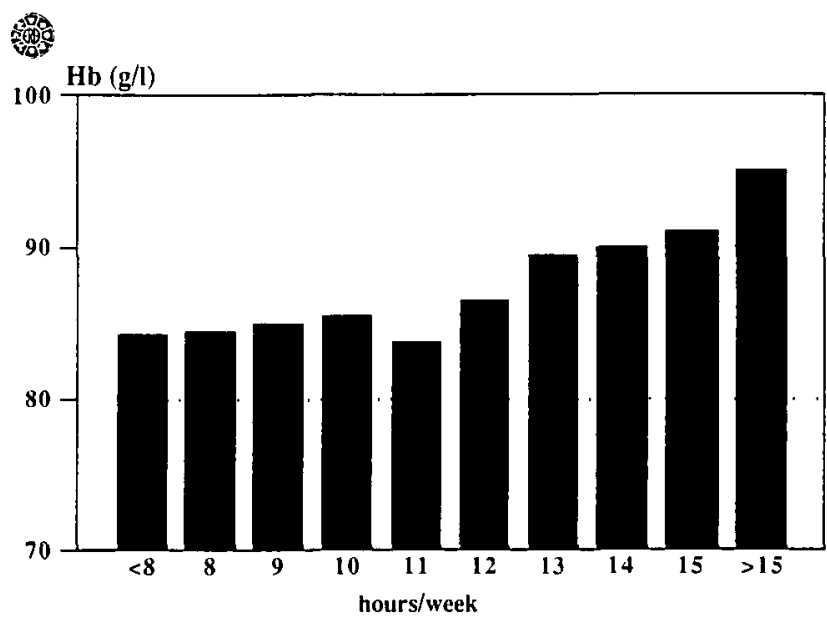

Fig. 5. Mean haemoglobin concentration related to number of hours haemodialysis per week.

tion $88.3 \mathrm{~g} / \mathrm{l}$ for patients on cellulose versus $88.5 \mathrm{~g} / \mathrm{l}$ for patients on non-cellulose membranes). In both groups the identical proportion of $17 \%$ needed regular transfusions.

A potential effect of porosity of the membrane was tested by grouping patients according to the ultrafiltration capacity of their dialyser. Patients dialysed with low-ultrafiltration dialysers $(<10 \mathrm{ml} / \mathrm{h} / \mathrm{mmHg}$ TMP $)$ were compared to those with medium ultrafiltration $(10-20 \mathrm{ml} / \mathrm{h} / \mathrm{mmHg}$ TMP) and to those dialysed with high ultrafiltration $(>20 \mathrm{ml} / \mathrm{h} / \mathrm{mmHg}$ TMP). Again, no significant association was obtained between ultrafiltration capacity and either the haemoglobin concentration $(P=0.10)$ or the need for transfusion $(P>0.10)$.

\section{Discussion}

Many factors have been associated with improvement of anaemia in patients undergoing dialysis for endstage renal disease. A progressive increase in haematocrit has been attributed to improved dialytic technique, to CAPD, to acquired cystic kidney disease, to hepatitis, to parathyroidectomy, and to treatment with androgens [4-10]. The introduction of rHuEpo enabled doctors partially to correct the normochromic normocytic anaemia complicating renal failure $[2,3]$. The efficacy of erythropoietin treatment is beyond dispute; however, optimizing dialysis treatment may minimize the requirement for the costly drug, allowing a reduction of the dosage needed for correction of renal anaemia.

This study was designed to help fill the gap in our knowledge regarding the influence of various factors on anaemia in dialysis patients using a representative sample drawn from our large database.

Significant associations were found between $\mathrm{Hb}$ concentration and primary renal disease, age, sex, type of last recorded treatment, length of time on treatment, number of dialysis sessions per week and hours of dialysis per week (although patients on three-times- 
weekly dialysis appeared to have a higher $\mathrm{Hb}$ concentration because of the larger number of dialysis hours per week).

The greater $\mathrm{Hb}$ concentrations recorded for patients on home haemodialysis and CAPD probably reflect patient selection and freedom from complicating illness. There have been reports that claim a beneficial role of CAPD itself on the anaemia of dialysis patients; an increase in red cell mass is reported by most authors $[13,14]$ whereas a decrease in plasma volume is infrequently reported [13]. There is no evidence for increased erythropoietin secretion in CAPD patients but there may be removal of inhibitors of erythropoiesis $[15,16]$. Increased red cell longevity is reported in several studies and may also contribute to the lesser degree of anaemia in CAPD patients [14].

The increase of $\mathrm{Hb}$ concentration with length of treatment could be explained simply by an increased mortality of the intrinsically less well, and so more anaemic, patients. However, an increase in $\mathrm{Hb}$ concentration has also been observed in dialysis patients with liver disease [6,7] and in association with acquired renal cyst formation [8], although the latter mechanism has been disputed [10].

One of the salient findings borne out by this study is the positive correlation between $\mathrm{Hb}$ concentration and number of hours spent on haemodialysis per week. That $\mathrm{Hb}$ concentration was greater in patients who received more than $12 \mathrm{~h}$ dialysis per week implies a role for the amount and the efficacy of dialysis on the degree of anaemia.

In the present study the use of dialysers with noncellulose membranes and high ultrafiltration capacity was not associated with a higher $\mathrm{Hb}$ concentration.

Of all patients evaluated, $16.5 \%$ needed regular transfusion, as expected. Among the more anaemic patients with $\mathrm{Hb}$ concentrations between 60 and $80 \mathrm{~g} / \mathrm{l}$ the proportion receiving regular transfusion was $28 \%$, of the less anaemic patients with $\mathrm{Hb}$ concentrations between 80 and $100 \mathrm{~g} / 1$ only $12 \%$ were regularly transfused. Transfusion policy may not always have followed strict rules, as financial, political, medical, and religious reasons exist which may inhibit blood transfusion, or even encourage the doctor to transfuse a patient to a higher $\mathrm{Hb}$ than his counterparts.

The risks associated with transfusion such as sensitization, transmission of infectious diseases, and possibly transfusion-induced erythroid suppression, should be weighed against the cost and side-effects of erythropoietin treatment. RHuEpo corrects anaemia in dialysis patients but this study demonstrates that rHuEpo should be used in conjunction with those management options which are themselves correlated with lessening of anaemia and reduced need for regular transfusion.

\section{References}

1. McGonigle RJS, Wallin JD, Shadduck RK. Erythropoietin deficiency and inhibition of erythropoiesis in renal insufficiency. Kidney Int 1984; 25: 437-444

2. Winearls CG, Oliver DO, Pippard MJ et al. Effect of human erythropoietin derived from recombinant DNA on the anaemia of patients maintained by chronic haemodialysis. Lancet 1986; 2: $1175-1178$

3. Eschbach JW, Egris JC, Downing MR et al. Correction of the anemia of endstage renal disease with recombinant human erythropoietin. Results of a combined phase I and II clinical trial. N Engl J Med 1987; 316: 73-78

4. Eschbach JW, Adamson JW, Cook JD. Disorders of red blood cell production in uremia. Arch Intern Med 1970; 126: 812-815

5. Santiago GC, Rao TKS, Laird NM. Effect of dialysis therapy on the hemotopoietic system; the national co-operative dialysis study. Kidney Int 1983; 23: S95-100

6. Brown S, Caro J, Erslev AJ et al. Spontaneous increase in erythropoietin and hemotocrit value associated with transient liver enzyme abnormalities in anephric patients undergoing hemodialysis. Am J Med 1980; 68: 280-284

7. Simon $\mathrm{P}$, Meyrier A, Tanguerei $\mathrm{T}$ et al. Improvement of anaemia in haemodialysed patients after viral or toxic hepatic cytolysis. Br Med J 1980; 280: 892-894

8. Goldsmith HJ, Ahmad R, Raichura N. Association between rising haemoglobin concentration and renal cyst formation in patients on long-term regular haemodialysis treatment. Proc Eur Dial Transplant Assoc 1983; 19: 313-318

9. Narasimhan N, Golper TA, Wolfson M. Clinical characteristics and diagnostic considerations in acquired renal cystic disease. Kidney Int 1986; 30: 748-752

10. Gliklich D, Kutcher R, Rosenblatt $\mathrm{R}$ et al. Time related increase in hematocrit on chronic hemodialysis; uncertain role of renal cysts. Am J Kidney Dis 1990; 15: 46-64

11. Cox DR. The Analysis of Binary Data. 1970. London, Methuen

12. Payne CD, ed. (1986). The GLIM System Rebase 3.77, Revision a. Oxford: Numerical Algorithms Group

13. De Paepe MBJ, Schelstraete KHG, Ringoir SMG et al. Influence of continuous ambulatory peritoneal dialysis on the anemia of endstage renal disease. Kidney Int 1983; 23: 744-748

14. Summerfield G, Bellingham A, Manlove L et al. Erythrocyte metabolism in patients on haemodialysis and continuous ambulatory peritoneal dialysis. Clin Sci 1982; 62: 479-488

15. Wideroe T-E, Sanengen T, Halvorsen S. Erythropoietin and uremic toxicity during continuous ambulatory peritoneal dialysis. Kidney Int 1983; 24: S208-S217

16. Lamperi S, Carozzi S, Icardi A. Perit Dial Bull 1983; 3: 94-96 